\title{
Autoinflammatory/Autoimmunity Syndrome Induced By Adjuvants (ASIA) Due to Silicone Incompatibility Syndrome
}

\author{
Genessis Maldonado $\left(\mathbb{D},{ }^{1}\right.$ Roberto Guerrero $\left(\mathbb{D},{ }^{1}\right.$ Maria Intriago $\mathbb{D}{ }^{2}$ and Carlos Rios $\mathbb{D}^{2}$ \\ ${ }^{1}$ Loyola MacNeal Hospital, Internal Medicine Residency Program, Maywood, IL, USA \\ ${ }^{2}$ Universidad Espiritu Santo, Rheumatology Department, Guayaquil, Ecuador \\ Correspondence should be addressed to Genessis Maldonado; genesismaldonadovelez92@gmail.com
}

Received 17 January 2021; Revised 25 July 2021; Accepted 11 August 2021; Published 16 August 2021

Academic Editor: Mehmet Soy

Copyright (c) 2021 Genessis Maldonado et al. This is an open access article distributed under the Creative Commons Attribution License, which permits unrestricted use, distribution, and reproduction in any medium, provided the original work is properly cited.

\begin{abstract}
The adjuvant-induced autoimmune syndrome (ASIA) is associated with a dysregulation of the innate and adaptive immune system after exposure to chemical compounds, including liquid paraffin, silicone gel, acrylamides, and hyaluronic acid. Due the increase of the use of these compounds in cosmetic procedures, the prevalence of this syndrome is increasing. We present the first report in Ecuador associated to ASIA after an elective silicone breast prosthesis procedure, manifested as polyarthralgia, positive antinuclear antibody, anticentromere antibody, and a moderate positive Sclero-70.
\end{abstract}

\section{Introduction}

A real-world analysis performed by Watad et al. showed an association between silicone breast implants (SBIs) and autoimmune/rheumatic disorders in a large populationbased database, and the strongest association with SBI was evidenced for Sjogren's syndrome, systemic sclerosis, and sarcodoisis [1]. Adjuvant-induced autoimmune syndrome or ASIA was recognized in 2011 with the aim of studying the growing appearance of disorders characterized by an innate and adaptive dysregulation of the immune system after exposure to adjuvants [2]. These compounds include liquid paraffin, silicone gel, acrylamides, hyaluronic acid, aluminum, and methacrylate derivatives. Symptoms of ASIA due to silicone incompatibility syndrome are fatigue, arthralgias, and cognitive impairment/memory loss [3].

Due to the growing trend of cosmetic procedures, it is important to recognize this association. A systematic search of the possible cases reported in the country was carried out. So far, there are no reports of the ASIA syndrome. It would seem that this would be one of the first reports made in the country. In addition, there are no official national registries for ASIA syndrome triggered by silicone prostheses.

\section{Case Report}

A 32-year-old female patient presented a 5-month history of polyarthralgia. The patient was evaluated by the trauma department due to a meniscal injury, and she was referred to the rheumatology department due to the presence of positive antinuclear antibodies. On physical examination, she presented polyarthralgia with a predominance of metacarpophalanges without swelling. As a relevant antecedent, the patient refers she underwent an abdominoplasty and breast augmentation with silicone implants placement approximately 5 years ago. Information regarding the implant brand is unknown. Initial laboratory tests showed a $1: 640$ positive antinuclear antibody, anticentromere antibody and a moderate positive Sclero-70. Immunoglobulin and IgG subclasses were not available (Table 1).

\section{Differential Diagnosis}

Because it is a recently described condition, this must be a diagnosis of exclusion. Diagnostic criteria for this condition were developed by Shoenfeld et al. [2]. To make the established diagnosis, the patient must meet at least two of the major criteria or one major and two minor criteria (Table 2). 
TABLE 1: Laboratory values.

\begin{tabular}{|c|c|c|}
\hline Laboratory studies & Results & Reference values \\
\hline \multicolumn{3}{|l|}{ Inflammatory markers } \\
\hline C-reactive protein & $10.73 \mathrm{mg} / \mathrm{dL}$ & $0.00-5.00 \mathrm{mg} / \mathrm{dl}$ \\
\hline \multicolumn{3}{|l|}{ Immunological } \\
\hline Antinuclear antibodies (ANA) HEp-2-IF & Positive 1: 640 , centromeric pattern to immunofluorescence & Positive $\geq 1: 40$ \\
\hline Anti-DNA ds, IF & Negative & Positive $\geq 1: 10$ \\
\hline Antimicrosomal antibodies (TPO) & $0.44 \mathrm{IU} / \mathrm{ml}$ & $0.00-4.61$ \\
\hline Interleukin-6 (IL-6) & $4.30 \mathrm{pg} / \mathrm{ml}$ & $\begin{array}{l}0-6.50 \mathrm{pg} / \mathrm{ml} \\
<20: \text { negative }\end{array}$ \\
\hline Sclero-70 antibodies & $46.67 \mathrm{U}$ & $\begin{array}{l}\text { 20-39: positive-weak } \\
\text { 40-80: positive-moderate } \\
\text { >80: positive-strong } \\
\text { <16: negative }\end{array}$ \\
\hline Anti-SSB (LA) (ELISA) & $1.86 \mathrm{U}$ & $\begin{array}{l}\text { 16-20: equivocal } \\
>20: \text { positive }\end{array}$ \\
\hline Anti-SM (ELISA) & $7.06 \mathrm{U}$ & $\begin{array}{c}\text { <20: negative } \\
\text { 20-39: positive-weak } \\
\text { 40-80: positive-moderate } \\
\text { >80: positive-strong } \\
\text { <20: negative }\end{array}$ \\
\hline Anti-RNP (ELISA) & $5.00 \mathrm{U}$ & $\begin{array}{l}\text { 20-39: positive-weak } \\
\text { 40-80: positive-moderate } \\
\text { >80: positive-strong } \\
\text { <20: negative }\end{array}$ \\
\hline Anti-JO & $3.60 \mathrm{U}$ & $\begin{array}{l}\text { 20-39: positive-weak } \\
\text { 40-80: positive-moderate } \\
\text { >80: positive-strong }\end{array}$ \\
\hline Rheumatoid factor- nephelometry & $<20.0 \mathrm{IU} / \mathrm{mg}$ & $0.00-20.0 \mathrm{IU} / \mathrm{mg}$ \\
\hline Citrullinated cyclic peptide antibody & $0.60 \mathrm{U} / \mathrm{mL}$ & Positive: $<5.0 \mathrm{U} / \mathrm{mL}$ \\
\hline Total vitamin $\mathrm{D}$ & $25.80 \mathrm{ng} / \mathrm{ml}$ & $\geq 30 \mathrm{ng} / \mathrm{dl}$ \\
\hline Antithyroglobulin antibodies & $5.48 \mathrm{IU} / \mathrm{ml}$ & $<4.5 \mathrm{UI} / \mathrm{mL}$ \\
\hline Complement C3 nephelometry & $115.00 \mathrm{mg} / \mathrm{dL}$ & $79.00-152.00 \mathrm{mg} / \mathrm{dL}$ \\
\hline Complement C4 nephelometry & $21.60 \mathrm{mg} / \mathrm{dL}$ & $16.00-38.00 \mathrm{mg} / \mathrm{dL}$ \\
\hline \multicolumn{3}{|l|}{ Hormonal Profile } \\
\hline Intact parathyroid hormone & $80 \mathrm{pg} / \mathrm{mL}$ & $18-116 \mathrm{pg} / \mathrm{mL}$ \\
\hline TSH- thyroid stimulating hormone & $0.7273 \mathrm{uUI} / \mathrm{mL}$ & Adults: $0.35-4.95$ \\
\hline T4- total thyroxine & $7.57 \mu \mathrm{g} / \mathrm{dL}$ & Adults: $4.90-11.70$ \\
\hline T3- total triiodothyronine & $1.19 \mathrm{nmol} / \mathrm{L}$ & Adults: $0.89-2.44$ \\
\hline \multicolumn{3}{|l|}{ Virology } \\
\hline Hepatitis delta IgM (EIA) & Negative & \\
\hline HBsAg- hepatitis B surface antigen & Not reactive & \\
\hline $\mathrm{HBcAc}$ - hepatitis $\mathrm{B}$, anticore $\operatorname{IgG} / \operatorname{IgM}$ & Not reactive & \\
\hline Hepatitis $\mathrm{C}$, antibodies & 0.03 & Reactive $>1$ \\
\hline
\end{tabular}

Table 2: Diagnostic criteria for ASIA syndrome.

\begin{tabular}{lc}
\hline Major criteria & Minor criteria \\
\hline Exposure to an external stimulus (adjuvants) before clinical & The appearance of autoantibodies or antibodies directed to the \\
manifestations & \\
\hline Appearance of "typical" clinical manifestations adjuvant
\end{tabular}


The patient was found to have two major criteria and one minor criterion, confirming the presence of the ASIA syndrome. Regarding collagen disease studies, a video capillaroscopy was performed, in which a pattern of normal characteristics was observed (Figure 1).

It was recommended to remove the breast implants, and the patient underwent removal of prosthesis approximately 6 months later; however, the presence of polyarthralgias and Raynaud's phenomenon were continued to be monitored.

\section{Discussion}

Silicone implants have been used since the 60 s as medical devices, whether they are intraocular lenses, heart valves, testicular, and joint and/or breast prostheses. Although their safety has been proven by several studies and public health institutions over the years, the presence of ASIA syndrome is possible in genetically prone patients.

The association that exists between breast implants and the immune system lies in the production and activation of $B$ and T cells and increased IgG antibodies and Th1/Th17 cells in the silicone capsule [4]. Furthermore, this material can induce an immunogenic response through cross reactions with natural glycosaminoglycans and molecules that contain silicone in connective tissue [4].

Because of this, the international registry of ASIA syndrome was created [5], and at the moment, there have been approximately 500 registered cases studied [6]; the majority were women, of which $69 \%$ developed defined autoimmune diseases (mixed connective tissue disease, Sjögren's syndrome, and scleroderma among others). $12.5 \%$ were exposed to silicone implants. The two most common diseases reported after exposure were differentiated connective tissue disease and Sjogren's syndrome [6]. Furthermore, the presence of positive antibodies was evidenced in $54.4 \%$ of the cases.

The set of symptoms that develop after exposure to silicone implants is known as siliconosis, and according to the reports by Boer et al., symptoms improve after implants are removed [7]; however, data from the work of Colaris et al. showed that the removal of the prosthesis temporarily alleviated the symptoms [3], and the authors also described that patients with ASIA and vitamin D deficiency were more prone to develop antibodies, as the patient presented in this case [3]. Wronski et al. reported a case of a 48-year-old woman with a history of breast implants and postexposure ASIA symptoms, with the presence of antinuclear antibodies, anticitrullinate, and Raynaud's phenomenon, and the patient underwent excision of the implants and the symptoms improved. However, Raynaud's phenomenon continued to be present, and the patient developed Hashimoto's thyroiditis [8]. Mejis et al. described improvement of systemic sclerosis symptoms after removal of the SBIs. Furthermore, the management of our patient will depend on the evolution after removal of the prostheses. Due to the presence of antinuclear, anticentromere, and Sclero-70 antibodies, it is important to evaluate the possible development of systemic sclerosis, hence the importance of knowing the relationship between silicone implants and the development of autoimmune diseases.

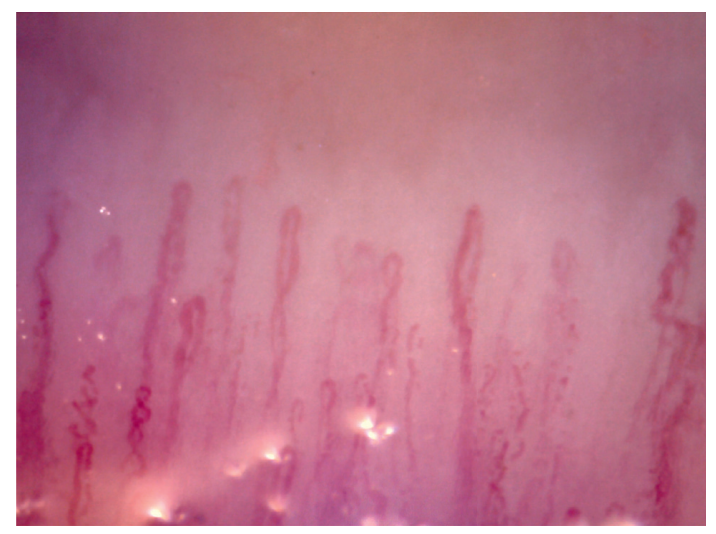

FIGURE 1: Normal pattern capillaroscopy adequate density without the presence of giant capillaries, avascular areas, or microhemorrhages.

\section{Conclusions}

This is the first case of ASIA due to silicone incompatibility syndrome described in Ecuador. The appearance of symptoms such as myalgias, fatigue, morning stiffness, and constitutional symptoms after exposure to breast implants should be evaluated in order to rule out ASIA syndrome. Those patients with a ruptured breast implant tend to have a more aggressive presentation compared to those with implants without alterations. Proper management is the removal of the implants, and if symptoms persist, diseasemodifying drugs, hydroxychloroquine, and glucocorticoids can be used.

\section{Data Availability}

The authors confirm that the data supporting the findings of this study are available within the article.

\section{Ethical Approval}

This study was approved by the Ethics and Teaching Committee of the Centro de Reumatología y Rehabilitación (CERER) (registration no: 007/2021; Folio 01: Book of Acts No. 1).

\section{Consent}

The patient signed inform consent for the release of the information mentioned in this case report.

\section{Conflicts of Interest}

The authors declare no conflicts of interest.

\section{Authors' Contributions}

C. Rios and G. Maldonado were responsible for case report conception and design. G. Maldonado, R. Guerrero, and Intriago $\mathrm{M}$ wrote the manuscript draft. C. Rios provided critical revision. 


\section{Acknowledgments}

The authors are part of the rheumatology department of the Universidad Espiritu Santo and Internal Medicine department of Loyola MacNeal Hospital.

\section{References}

[1] A. Watad, V. Rosenberg, S. Tiosano et al., "Silicone breast implants and the risk of autoimmune/rheumatic disorders: a real-world analysis," International Journal of Epidemiology, vol. 47, no. 6, pp. 1846-1854, 2018.

[2] Y. Shoenfeld and N. Agmon-Levin, "ASIA-autoimmune/inflammatory syndrome induced by adjuvants," Journal of Autoimmunity, vol. 36, no. 1, pp. 4-8, 2011.

[3] M. J. L. Colaris, M. de Boer, R. R. van der Hulst, and J. W. Cohen Tervaert, "Two hundreds cases of ASIA syndrome following silicone implants: a comparative study of 30 years and a review of current literature," Immunologic Research, vol. 65, no. 1, pp. 120-128, 2017.

[4] A. Watad, M. Quaresma, S. Brown et al., "Autoimmune/inflammatory syndrome induced by adjuvants (Shoenfeld's syndrome)-an update," Lupus, vol. 26, no. 7, pp. 675-681, 2017.

[5] A. Watad, M. Quaresma, N. L. Bragazzi et al., "The autoimmune/inflammatory syndrome induced by adjuvants (ASIA)/ Shoenfeld's syndrome: descriptive analysis of 300 patients from the international ASIA syndrome registry," Clinical Rheumatology, vol. 37, no. 2, pp. 483-493, 2018.

[6] A. Watad, N. L. Bragazzi, D. McGonagle et al., "Autoimmune/ inflammatory syndrome induced by adjuvants (ASIA) demonstrates distinct autoimmune and autoinflammatory disease associations according to the adjuvant subtype: insights from an analysis of 500 cases," Clinical Immunology, vol. 203, pp. 1-8, 2019.

[7] M. de Boer, M. Colaris, R. R. W. J. van der Hulst, and J. W. Cohen Tervaert, "Is explantation of silicone breast implants useful in patients with complaints?" Immunologic Research, vol. 65, no. 1, pp. 25-36, 2017.

[8] J. Wroński, K. Bonek, and E. Stanisławska-Biernat, "Scleroderma-like syndrome in a woman with silicone breast implants-case report and critical review of the literature," Reumatologia, vol. 57, no. 1, pp. 55-58, 2019. 